The influence of reading instruction on language and memory development in children with

\section{Down's syndrome}

\section{Glynis Laws, Sue Buckley, Gillian Bird, John MacDonald and Irene Broadley}

\author{
Department of Psychology, \\ University of Portsmouth, \\ U.K.
}

\begin{abstract}
This paper reports evidence for the importance of reading instruction for memory and language development in children with Down's syndrome. Language and memory measures for 14 children were obtained over nearly four years as part of our research investigating the effect of teaching memory strategies. Half of the children were readers or became readers in the course of the study. At the start of the study, there were no significant differences between readers and non-readers in vocabulary and grammar understanding, or in auditory and visual memory performance. By the end of the study, a significant advantage for the readers was noted for all language and memory measures. Possible reasons for these findings are discussed, as well as the implications for educational intervention.
\end{abstract}

\section{Acknowledgements}

The authors would like to thank the parents, teachers, and children who took part in this study. The collection of data from the early part of the study was funded by a bursary from The Portsmouth Down's Syndrome Trust to Irene Broadley. The follow up study was funded by a grant from the University of Portsmouth.

(C) 1993, 1999. The Down Syndrome Educational Trust Down Syndrome Research and Practice

1995, 3 (2) 59-64

\section{Introduction}

Since 1966 there have been reports in the literature suggesting that children with Down's syndrome can achieve functional levels of literacy and that reading might accelerate speech and language acquisition (Duffen, 1976; Orme, Fisher \& Griggs, 1966; Rhodes, Gooch, Siegelman, Behrns \& Metzger, 1969; Saunders \& Collins, 1972). All these authors used case study evidence to argue for the effect of reading on spoken language. For example, Duffen (1976), when describing the progress of his daughter Sarah, observed: "Sarah's reading ability has considerably helped the development of her speech. The critical discovery was that Sarah read, remembered and later used, in the correct context, sentences that she was incapable of remembering when she just heard them."

Saunders and Collins (1972) also claimed that reading benefited spoken language: "It would be true to say that through our work we have taught some children to speak through teaching reading".

More recently, Buckley (1995a) has argued that reading should also lead to an improvement in short term memory span. This influence of reading progress on speech, language and memory skills would be predicted from the study of typically developing children. Being able to read opens up access to knowledge and leads to the biggest vocabulary explosion for children between the ages of 7 and 16, when children are typically learning around 3,000 words each year (Nagy \& Herman, 1987).

Garton and Pratt (1989) stress the close inter-relationship between spoken and written language, pointing out that experience with both these forms will contribute to further language development. Buckley's studies with adolescents with Down's syndrome (Buckley, 1993, 1995b) showed how teaching which used printed sentences provided more effective support in improving grammar production and comprehension than teaching which used speech and pictures.

Studies of reading development in typically developing children suggest reciprocal interactions between reading progress, language and memory skills (Ellis \& Large 1988; Gathercole \& Baddeley, 1993). Longitudinal studies have demonstrated that beginning readers' language knowledge, phonological awareness and working memory skills influence reading progress during the first year of reading instruction. In turn, the better readers at the start of the second year show the biggest gains in working memory and phonological awareness by the end of the year (Ellis \& Large, 1988). Gathercole and Baddeley (1993) reviewed many studies of the links between phonological processing and reading. They found the evidence suggested "...that reading and phonological awareness, and reading and phonological memory, develop in mutually facilitative fashions."

Until very recently, it would have been difficult to establish a longitudinal study to look at the effect of reading progress on other cognitive skills in children with Down's syndrome, as the majority were not being taught to read. With the recent shift in education provision toward mainstreaming the children, longitudinal studies are becoming possible; another paper in this issue describes the early data from one such study (Byrne, Buckley, MacDonald and Bird, 1995). In Byrne et al's study, all the children are being taught to read. The shift 
to mainstream placement of the primary aged children with Down's syndrome has been so rapid in this part of the UK that the majority are in mainstream schools. Since they are all taught reading, this means it is no longer feasible to set up a local study to compare the cognitive development of children with Down's syndrome being taught to read with those who are not receiving literacy instruction.

However, during this transition in our local education provision from 1990 to 1995, we have collected data which has made such a comparison possible. Reading, memory and language data have been collected over nearly four years from 14 children with Down's syndrome, 7 of whom are now reading. These children are part of a larger group which participated in research on developing memory strategies. The data provide the opportunity to observe differences in language and memory progress over this period which could be attributed to reading status. Since all but one of the readers in this group attend mainstream school, reading is confounded with educational experience. However, we also present data from initial pre-training assessments for the larger group which allow us to look at these differences for children who all attend special schools.

\section{Method}

\section{Subjects}

The subjects had been assessed originally as part of a project to train children with Down's syndrome to use memory strategies (Broadley, 1994; Broadley and MacDonald, 1993; Broadley, MacDonald and Buckley, 1994; Broadley, MacDonald and Buckley, 1995). They formed part of a group of 51 children who received pre-training assessments in October 1991. After assessment, half were assigned to be trained while the other children became an untrained control group. All these children were assessed a number of times to measure the effect of the training and to compare the performance of the trained children with the performance of the control children. The final investigation of this project followed up 14 of the trained children to investigate long term maintenance of the trained memory skills in July 1995 (Laws, MacDonald, Buckley and Broadley, in press). As a result we have longitudinal data for these children plotting their memory and language development over more than three and a half years.

\section{Procedure}

Full details of the testing and training procedures are reported elsewhere (Broadley, 1994; Broadley and MacDonald, 1993). This paper is concerned with results obtained from a subset of the tests presented: British Picture Vocabulary Scale (BPVS); Test for the Reception of Grammar (TROG); Raven's Coloured Progressive Matrices (Matrices); British Ability Scales reading test; and auditory and visual word span measures. The word span measures were obtained from serial recall tasks where the child was asked to repeat sequences of one-, two- and three-syllable words. The sequences were presented under two conditions: the words were spoken by the experimenter and the child was required to repeat them; or they were presented to the child as pictures. For the visual presentation, each picture in a sequence was laid before the child one at a time and its name spoken by the experimenter. The pictures were then turned over and the child was asked to recall the sequence verbally.
The 14 children were categorised as readers or non-readers on the basis of whether or not they had scored anything on the BAS reading test at the follow-up assessment. 7 of the children were classed as readers. Their scores ranged from 3 to 39 with a mean score of $21(S D=12.62)$. We were also interested in the type of school the children attended. The majority of the original sample attended special schools but six of the fourteen children in the follow-up group were at mainstream schools.

\section{Results}

\section{The measures}

The ages of the children ranged from 8 years 8 months to 14 years 10 months. The average age of the readers was 10 years 2 months; and the average age of the non-readers was 11 years 5 months. There was no significant difference between the mean ages of the groups.

Raw scores for each of the standardised tests used were recorded and means across subjects for readers and nonreaders were calculated separately and used in the analyses reported below. For the memory tests, word spans under each condition were calculated as means across the three syllable lengths to give an auditory memory score and a visual memory score. Table 1 shows the mean scores achieved on these assessment measures in 1991 and 1995 by each group.

\section{Cognitive effects}

Our main question is whether learning to read enhances vocabulary and grammar understanding and memory performance. If it does, we would expect readers' performance on tests of vocabulary, grammar and memory to be superior to the performance of non-readers. Furthermore, if the difference in performance is to be attributed to the reading rather than to some underlying difference in language abilities between the children (in other words if the reading produced better language skills rather than those with better language abilities going on to become readers), we should find a difference between the groups for the most recent assessment scores but less difference in the abilities of the two groups at the beginning of the study when only three of the children had started reading.

We examined this question, using a series of mixed two-way analyses of variance (ANOVA's) to investigate the differences between means for each of the measures of interest with reading as a between-groups factor (readers versus non-readers) and time of measurement as a within-subjects factor (1991 versus 1995).

\section{Non-verbal ability}

First, we will deal with the analysis of Matrices scores. As a measure of non-verbal intelligence, we would not expect the teaching of reading to have a direct impact on scores achieved on this test. The means reported in Table 1 suggest this to be the case as we see little difference between the groups while both readers and non-readers show an increase in scores over time. The ANOVA confirms this impression: there is a highly significant main effect of time $(F=25.61$; $\mathrm{df}=1,10 ; p=.000)$ but no main effect for reading $(F=.48$; $\mathrm{df}=1,10 ; \mathrm{p}=.503)$ and no interaction $(F=.02 ; \mathrm{df}=1,10$; $p=.899)$. Thus there are no differences between the groups 
Table 1: Mean matrices, language and memory scores for readers and nonreaders in 1991 and 1995.

\begin{tabular}{|l|l|l|l|l|}
\hline \multicolumn{5}{|c|}{ October 1991 July 1995 } \\
\hline & $\begin{array}{l}\text { Readers } \\
(\mathrm{N}=7)\end{array}$ & $\begin{array}{l}\text { Non-readers } \\
(\mathrm{N}=7)\end{array}$ & $\begin{array}{l}\text { Readers } \\
(\mathrm{N}=7)\end{array}$ & $\begin{array}{l}\text { Non-readers } \\
(\mathrm{N}=7)\end{array}$ \\
\hline Matrices & $2.83(2.31)$ & $1.68(.52)$ & $12.83(7.0)^{*}$ & $11.17(6.31)^{*}$ \\
\hline BPVS & $7.43(2.99)$ & $5.57(2.15)$ & $11.71(2.43)$ & $6.86(3.29)$ \\
\hline TROG & $3.71(2.14)$ & $2.14(1.22)$ & $6.57(2.37)$ & $2.86(2.61)$ \\
\hline Auditory Memory & $1.48(.54)$ & $1.43(.37)$ & $2.62(.36)$ & $1.62(.62)$ \\
\hline Visual Memory & $1.48(.42)$ & $1.48(.46)$ & $2.76(.25)^{*}$ & $1.89(.50)$ \\
\hline$\left({ }^{*} \mathrm{~N}=6\right)$ & & & & \\
\hline
\end{tabular}

on this measure of non-verbal intelligence and both show the same developmental progress over time.

\section{Vocabulary}

The analysis of mean scores on the BPVS showed a different pattern of results. Again, we see a main effect for time $(F=13.19 ; d f=1,12 ; p=.003)$, but reading also has a significant effect on means $(F=10.49 ; d f=1,12 ; p=.007)$. An interaction between time of measurement and reading approached significance $(F=3.82 ; d f=1,12 ; p=.074)$. Vocabulary scores for the readers are tending to diverge from those of the non-readers. Whereas there was a difference of less than two items between the groups in 1991, the difference in 1995 was nearly five items.

\section{Grammar}

This pattern of results is even more marked for scores on the TROG test; over time the non-readers have progressed by an average of less than one block on the TROG, whereas the difference in the readers' scores was nearly three blocks. Analysis of variance confirms the significant main effect for time $(F=12.10 ; d f=1,12 ; p=.005)$ and for reading $(F=6.61$; $\mathrm{df}=1,12 ; p=.024)$. Again the interaction between reading status and time of assessment approaches significance $(F=4.35 ; d f=1,12 ; p=.059)$.

\section{Memory}

As we can see in Table 1, auditory memory measures were almost identical for the two groups at the start of the study but the final assessment reveals an advantage for the readers. Analysis of variance shows a significant effect for time $(F=10.27 ; \mathrm{df}=1,12 ; \mathrm{p}=.008)$ and also for reading $(\mathrm{F}=11.43$; $\mathrm{df}=1,12 ; p=.005)$. There is a significant interaction between time of assessment and reading $(F=5.24 ; \mathrm{df}=1,12 ; \mathrm{p}=.041)$ reflecting the increased performance of the readers compared with that of the non-readers at the 1995 assessment.

A similar pattern of results was found for the visual memory scores - a much greater difference between the groups at the end of the period than existed at the beginning. The ANOVA confirms the main effect for time $(F=29.69 ; \mathrm{df}=1,11 ; \mathrm{p}=.000)$ and also for reading $(F=9.14 ; d f=1,11 ; p=.012)$. Once again we found a significant interaction between these two main effects $(F=5.75 ; d f=1,11 ; p=.035)$ reflecting the much wider difference between the 1991 and 1995 scores of the readers compared with the difference found for the non-readers.

\section{Interactions}

To investigate the interactions, we looked at the difference between the 1991 and 1995 scores for each group separately using paired-sample ttests. For the non-reading group, there was no significant increase over time in their performance on any of the measures except Matrices. In contrast, the readers showed statistically significant gains over time on all the measures.

Table 1 suggests that the readers were already slightly more advanced in 1991. We compared their performance at that time with that of the non-readers using independent groups t-tests to examine the differences in mean scores for all the measures. In 1991, no significant differences were found between readers and non-readers on any of our measures. In contrast, independent groups ttests used to examine the difference between the groups' mean scores in 1995 showed that the readers scored statistically significantly higher than non-readers on all the measures of interest, except the Matrices. (BPVS: $p=.002$; TROG: $p=.017$; auditory memory: $p=.003$; visual memory: $p=.006)$. Thus groups of children who started out in 1991 with much the same average scores on our assessment measures had become quite different from each other by 1995.

\section{Time of effect}

We were interested in seeing at what point the memory scores of the readers had begun to diverge from those of the non-readers. Since these data were collected primarily to evaluate the effects of training a rehearsal strategy, we have assessments carried out immediately post-training in summer 1992, and then some eight months later in spring 1993. Table 2 shows the full picture of memory scores over time. Across all the subjects included in the follow-up study, we found that the significant gains in memory performance produced by the training had been much reduced. Since the children had not continued with the memory training procedures this was probably to be expected. However, if we look separately at readers and non-readers we see that posttraining memory performance was much the same for both groups but, whereas the memory measures for the nonreaders had returned almost to pre-training levels by 1995 , the readers had sustained much of the training gain.

\section{Size of gains}

Of course, apart from the statistical significance so far discussed, we are interested in the real significance of these effects; what do such differences on these tests signify in terms of developmental progress? Perhaps one way to consider this is to convert the raw scores on the standardised tests to the age-equivalent scores shown in Table 3 . This shows that the real difference between the groups is that the readers are on average 1 year 9 months ahead on vocabulary understanding, and an average of at least 1 year and 4 months ahead on their level of grammar understanding. 
Table 2. Mean auditory and visual memory scores for readers and non-readers (s.d.'s in brackets)

\begin{tabular}{|c|c|c|c|c|}
\hline & $\begin{array}{l}\text { Pre-training } \\
\text { Oct. } 1991\end{array}$ & $\begin{array}{l}\text { Post-training } \\
\text { June } 1992\end{array}$ & $\begin{array}{l}\text { Eight months later } \\
\text { March } 1993\end{array}$ & $\begin{array}{l}\text { Three years later } \\
\text { June } 1995\end{array}$ \\
\hline Non-readers & $1.43(.37)$ & $2.14(.42)$ & $2.10(.25)$ & $1.62(.62)$ \\
\hline Readers & $1.48(.54)$ & $2.05(.56)$ & $2.43(.90)$ & $2.62(.35)$ \\
\hline \multicolumn{5}{|c|}{ b) Visual Memory Span } \\
\hline & $\begin{array}{l}\text { Pre-training } \\
\text { Oct.1991 }\end{array}$ & $\begin{array}{l}\text { Post-training } \\
\text { June } 1992\end{array}$ & $\begin{array}{l}\text { Eight months later } \\
\text { March } 1993\end{array}$ & $\begin{array}{l}\text { Three years later } \\
\text { June } 1995\end{array}$ \\
\hline Non-readers & $1.48(.42)$ & $3.24(.63)$ & $3.00(1.10)$ & $1.89(.50)$ \\
\hline Readers & $1.48(.46)$ & $3.38(.93)$ & $3.71(1.18)$ & $2.76(.25)$ \\
\hline
\end{tabular}

No comparable age norms are available for the memory measures but we can compare the word spans achieved with those reported by earlier researchers for normally developing children. Hitch and Halliday (1983) report word spans averaged across three syllable lengths of 2.4 for spoken sequences and 2.2 for picture sequences for 6 year old subjects. Henry (1994) found an average word span of just over 3 single syllable words for a group of 5 year olds. Cowan, Saults, Winterowd and Sherk's (1991) 4 year olds had mean word spans of 3.41 for single syllable spoken word lists, whereas the four year old subjects in Hulme, Thomson, Muir and Lawrence's (1984) experiment had mean spans of about 2 at this word length, and less for longer words. No doubt the variations in word spans reported in the literature reflect differences in stimuli used and procedures. However, in the general context of the available data, the memory spans of our reading group seem to be in line with

Table 3. Age equivalent scores for 1995 BPVS and TROG measures for readers and non-readers.

\begin{tabular}{|l|l|l|}
\hline & Readers & Non-readers \\
\hline $\begin{array}{l}\text { Vocabulary } \\
\text { (BPVS) }\end{array}$ & 4 yrs 11 mnths & $3 \mathrm{yr} 2$ mnths \\
\hline $\begin{array}{l}\text { Grammar } \\
\text { (TROG) }\end{array}$ & 4 yrs 4 mnths & $<3$ yrs \\
\hline
\end{tabular}

their functional language level.

\section{Reading or school?}

So far, we have identified our two groups of children as either readers or non-readers. In fact, the reading status of the children was almost completely confounded by the type of school attended. All but one of the readers were at mainstream schools, whereas all of the non-readers attended special schools. This is a problem for our hypothesis that it is the reading itself which has produced these differences in the language and memory measures. The children at mainstream schools have a different educational experience which goes beyond the opportunity to learn to read. It could be that our results are explained by the fact that the mainstream children are developing in a normal language environment and that growing up with peers following normal patterns of language acquisition is what really boosts the language performance of children with Down's syndrome. This is an important question which, fortuitously, we are able to examine, albeit in a limited way. Although just one of the special school children in our follow-up study scored on the BAS reading test, there were many children in the initial large sample who were attending a special school and who were also readers. This gives us the opportunity to compare readers with non-readers under conditions where the two groups enjoy similar educational environments.

\section{Special school readers}

For our analysis we selected all the children attending special school in 1991 who were within approximately the same age range as those in the longitudinal sample reported above. Their ages ranged from 8 years 4 months to 14 years 9 months with a mean age of 11 years 6 months. The average age of the readers was 12 years 1 month, and of the non-readers 10 years 11 months. As before, the criterion for being placed in the reading group was that the child scored something on the BAS reading test; 17 of the children were classified as readers and 17 as non-readers. The range of reading scores achieved was from 1 to 75 with a mean of $26.56(S D=24.95)$. Table 4 shows the scores for readers and non-readers on the language and memory measures. Comparing these means with the 1995 results reported in Table 1, there is a close similarity in the average scores both for readers and non-readers.

Table 4: Language and memory measures for special school readers and non-readers.

\begin{tabular}{|l|l|l|l|}
\hline & $\begin{array}{l}\text { Readers } \\
(\mathrm{N}=17)\end{array}$ & $\begin{array}{l}\text { Non-readers } \\
(\mathrm{N}=17)\end{array}$ & Difference \\
\hline $\begin{array}{l}\text { Vocabulary } \\
\text { (BPVS) }\end{array}$ & $11.29(3.90)$ & $7.71(2.02)$ & $\begin{array}{l}3.58 \\
(\mathrm{p}=.007)\end{array}$ \\
\hline $\begin{array}{l}\text { Grammar } \\
\text { (TROG) }\end{array}$ & $6.82(2.27)$ & $3.51(1.23)$ & $3.31(\mathrm{p}=000)$ \\
\hline $\begin{array}{l}\text { Auditory } \\
\text { memory }\end{array}$ & $2.45(.42)$ & $1.63(.37)$ & $.82(\mathrm{p}=.000)$ \\
\hline $\begin{array}{l}\text { Visual } \\
\text { memory }\end{array}$ & $2.37(.44)$ & $1.65(.53)$ & $.72(\mathrm{p}=.001)$ \\
\hline
\end{tabular}


The differences between the mean scores for readers and non-readers were investigated using simple factorial ANOVAs with reading as a between groups factor and age treated as a covariate since at least some of the variance in these scores seemed likely to be attributed to age. For each measure, reading was shown to be a significant factor (BPVS: $F=8.2 ; p=.007$; TROG: $F=23.62 ; p=.000$; Auditory memory: $F=29.79 ; p=.000$; Visual memory: $F=14.10$; $\mathrm{p}=.001)$. Age was also shown to contribute to the variance for all measures except the BPVS.

These analyses confirm that when readers and non-readers from similar educational environments are compared, readers score significantly higher on tests of language ability and memory capacity.

\section{Discussion}

Our results suggest that learning to read has a significant impact on language progress and on the development of auditory and visual memory skills. The longitudinal data show that, nearly four years after starting out with similar levels of vocabulary and grammar understanding, the readers have made considerably more progress in their language development. This new evidence supports the case study records which suggest that reading encourages improved grammar in speech.

Given the opportunity to increase language knowledge that reading provides it is not surprising to find these advances. Most of the readers in the longitudinal study started reading using an approach recommended by the Sarah Duffen Centre. This differs from other approaches by deliberately using reading to teach new words and concepts. The children begin by learning a small sight vocabulary of words with which they are familiar, but then move on to learning new words which are not yet in their speech repertoire. Thus spoken and reading vocabularies advance together. A further important feature of this approach is the early introduction of short sentences for reading which can then be practised and used in everyday speech, and which add to the children's knowledge of grammar. This is the area of language learning which gives children with Down's syndrome the greatest difficulty (Chapman, 1995; Fowler, 1990).

For children with Down's syndrome, the visual representation of language offers a way to overcome their auditory processing and memory difficulties. In contrast to spoken language, printed text provides a permanent rather than a transitory signal. This allows more processing time, and gives the child a better chance of learning.

Our cross-sectional data comparing the memory measures for children at special schools reflects the evidence from typically developing children in studies comparing good and poor readers (e.g. Mann, Liberman and Shankweiler, 1980). These show that better readers also perform better on tests of memory involving verbal material and that poor readers may show memory deficits. In our study, we compared those who can read anything at all with non-readers with similar results - significantly higher mean memory scores for the readers. This evidence alone would be difficult to interpret since it could be just as easily argued that only those children with better memory capacity were able to read. Indeed, Fowler (1994) has suggested that a digit span of 4 may be needed for the successful development of reading skills.
However, the longitudinal data overcome the problems of interpretation, and show that rather than some minumum memory capacity be required for reading as Fowler suggests, that reading itself will promote the development of memory skills. Children in our study groups began with very similar, extremely low, scores on our memory measures. Nearly four years later, those who have received reading instruction are clearly diverging from the non-readers. Despite improvements in memory scores, none of the readers had a word span average more than 3 (this measure was the average word span across three syllable lengths) and, at the start of the study, only one of them had an average span as much as 2 . It would therefore be a great mistake to withhold reading instruction from children from Down's syndrome while waiting for them to attain some minimum level of memory capacity.

The ways in which speech, language and memory development are mutually facilitated could not be addressed in this limited study, but it is a research priority to find out more about these relationships. Our own speculation, based on reading research with typically developing children, would be that increased memory capacity comes about as a result of the development of alphabetic reading strategies which the mainstreamed children will be taught at school. Sounding out a word letter by letter requires working memory capacity to hold the early sounds in the word long enough to decode the whole word. If this does account for the readers' memory performance, we might further speculate that alphabetic reading could have provided working memory practice and helped maintain the trained memory performance. In addition, if members of the reading group have developed alphabetic strategies, there is the possibility that the memory training may have actually contributed to this ability. Angela Byrne's research programme, the early results of which are published elsewhere in this issue, will hopefully provide further insights into how these complex relationships between reading, language and memory develop.

Although these results are based on data from a relatively small number of children, we believe they clearly support the arguments for the importance of teaching children with Down's syndrome to read. Furthermore, despite the apparent failure to maintain the effects of rehearsal training in the long term for the group as a whole, it may also be important to include continued memory training for this group. Memory is clearly intimately tied to language and literacy development and interventions designed to improve any one of these abilities could benefit the others.

\section{References}

Broadley, I. W. (1994). Teaching Short-term Memory Skills to Children with Down's Syndrome. PhD thesis. Portsmouth, U.K.: University of Portsmouth.

Broadley, I.W. and MacDonald, J. (1993). Teaching shortterm memory skills to children with Down's syndrome.Down's syndrome: Research and Practice, 1(2) 56-62.

Broadley,I.W., MacDonald,J. and Buckley,S. (1994). Are children with Down's syndrome able to maintain skills learned from a short-term memory training programme? Down's syndrome: Research and Practice, 2 (3) 116-122.

Broadley,I.W., MacDonald,J., and Buckley,S.(1995). Working memory in children with Down's syndrome. Down's syndrome: Research and Practice, 3 (1) 3-8. 
Buckley,S. (1993). Developing the speech and language skills of teenagers with Down's syndrome. Down's Syndrome: Research and Practice. 1 (2) 63-71.

Buckley, S. (1995a). Invited paper: Reading and writing in Down syndrome. EDSA Third International Down's Syndrome Symposium, Mallorca, Spain. In J.A. Rondal, L. Nadel and J. Perrera (Eds) Down Syndrome: Psychological, psychobiological and socioeducational perspectives. London: Whurr.

Buckley, S. (1995b). Increasing the conversational utterance length of teenagers with Down's syndrome. Down's syndrome: Research and Practice, 3 (3). In press.

Byrne,A., Buckley,S., MacDonald,J., and Bird,G. (1995). Investigating the literacy, language and memory skills of children with Down's syndrome and their mainstream peers. Down's Syndrome: Research and Practice, 3 (2) 53-58.

Chapman,R.S. (1995). Language development in children and adolescents with Down syndrome. In P. Fletcher and B. MacWhinney (Eds) The Handbook of Child Language. Oxford: Blackwell Publishers.

Cowan,N., Saults,J.S., Winterowd,C., and Sherk,M.(1991). Enhancement of 4-year-old children's memory span for phonologically similar and dissimilar word lists. Journal of Experimental Child Psychology, 51, 30-52.

Duffen,L. (1976). Teaching reading to teach language. Remedial Education. 11, 3, 139-142.

Ellis,N., and Large,B. (1988). The early stages of reading: a longitudinal study. Applied Cognitive Psychology, 2, 4776.

Fowler,A.E. (1990). Language abilities in children with Down syndrome: evidence for a specific syntactic delay. In D. Cicchetti and M. Beeghly (Eds) Children with Down Syndrome. Cambridge: Cambridge University Press.

Fowler,A.E. (1994) Reading, phonemic awareness and phonological memory in children with Down syndrome. First International Conference on Language and Cognitive Development in Children and Adults with Down's Syndrome, Portsmouth.

Garton,A. and Pratt,C. (1989). Learning to be Literate: the Development of Spoken and Written Language. Oxford: Blackwell Publishers Ltd.

Gathercole,S.E. and Baddeley,A.D. (1993).Working Memory and Language. Hove: Lawrence Erlbaum Associates.
Henry,L. (1994). The relationship between speech rate and memory span in children. International Journal of Behavioral Development, 17, 1, 37-56.

Hitch,G.J. and Halliday,M.S. (1983). Working memory in children. Philosophical Transactions of the Royal Society, Series B., 302, 324-340.

HulmeC., Thomson,N., Muir,C., and Lawrence,A. (1984). Speech rate and the development of short-term memory span. Journal of Experimental Child Psychology, 38, 241253.

Laws,G., MacDonald,J., Buckley,S. and Broadley,I. (1995). Long term maintenance of trained memory strategies in children with Down's syndrome. Down's Syndrome: Research and Practice, 3 (3). In press.

Nagy,W.E. and Herman,P.A. (1987). Breadth and depth of vocabulary knowledge: implications for acquisition and instruction. In M.G. McKeown \& M.E. Curtis (Eds.), The Nature of Vocabulary Acquisition. Hove: Lawrence Erlbaum Associates

Mann,V.A., Liberman,I.Y. and Shankweiler,D.(1980). Children's memory for sentences and word strings in relation to reading ability. Memory and Cognition, 8, 329-335.

Orme,J.E., Fisher,F.J.S., and Griggs,J.B. (1966). The big words. New Education, 12, 25-26.

Rhodes,L., Gooch,B., Siegelman,E.Y., Behrns,C. and Metzger,R. (1969). A Language Stimulation and Reading Program for Severely Retarded Mongoloid Children. California Mental Health Research Monograph, 11. State of California, Department of Mental Hygiene.

Saunders,J. and Collins,J. (1972). Teaching Mentally Handicapped Children. Hove: Penny Gobby House School.

Address for correspondence:

Dr Glynis Laws,

Sarah Duffen Centre,

Belmont Street,

Southsea,

Hants, PO5 1NA.

U.K. 